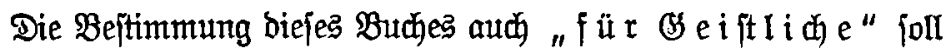

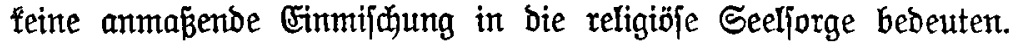
Der Berfajper glaubt einem ihm mehrfach von geiflicher Seite ge= äuperten Bebürfnis zu entiprechen, wenn er ipeziell bem Seeljorger in Brofisftäbten einiges Material für bie angemanote Sittenlehre zur Berfügunt ftellt.

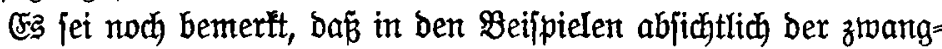
iofe Ton ber Bcfpredung feftgehalten tworben ift; Wieberholungen

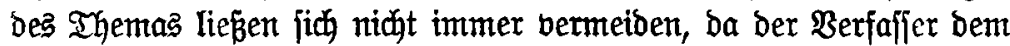
Lehrer für bejtimmte (5intwirfungen möglidjt mannigfaltige Bariationen zur Berfügung ftellen wollte. Die Beifpiele fino für Sntraben und Mäbden von 11-15 sahren gedadyt uno erfheinen mit menigen

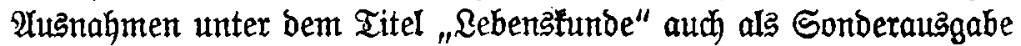
bireft für ben Bebrauch Der Эugent.

8üridh, ben 1. Dlai 1904.

Dex Berfajier.

\title{
3weite Bortwort.
}

Seit bem Exfdyeinen bes vorliegenben Butyes find nun faft brei Jahre verfloffen. We liegt nahe, baß ber Berfaffer die Belegenheit eines Reubruds benubt, um gegentiber ben Benteilungen, bie fein Bub in ben verifiedenen Ragern gefunden hat, noch einmal hurz bie Brnmbanichauming zu betonen und zu berteibigen, bon ber feine pãdagagï̆he $\mathfrak{A}$ rbeit getragent wirb.

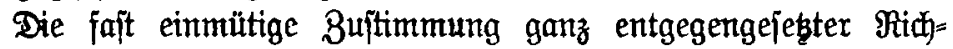
tungen hat wohl beutlid betwiejen, wie widjtig es ift, gerabe in bem Beitalter ber leibenjinaftlidjten SHaubenstremungen an einen noch

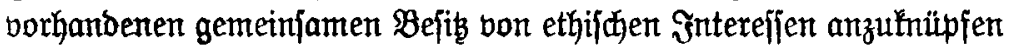
und bie Menidhen bon bort aus zu jener Selbiterfenntris und Rebens fenntnis zunüfơleiten, bie allein mieder ein tieferes Beritänonis ber

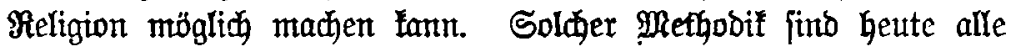
ftreitenden \$arteien gleidh bedürtig: bie (Glaubenstojen, weil fie aus Mangel an $\mathfrak{B}$ ertief $\mathfrak{n} \mathfrak{g}$ in bie Brumbfragen ber etfifiden Er. 
Bormort.

ziehung und Selbjterziehung bie Religion gar nidjt mehr verjtehen: die Bertreter bes Blaubens, weil fie ihre Rebensanthaumng nidit mehr lebenbig barzuftellen bermögen, zu wenig bon ber einfachjten ethilitien Erfahrung ausgehen, zu jehr bebuftio und zu menig inouftio lehren uno interpretieren.

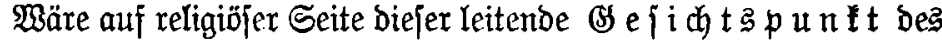
Buthes mehr beachtet und heraugagefühlt worben, jo hätten mandije

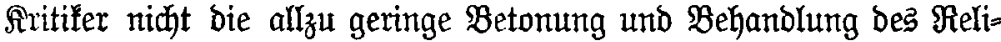
giöjen bemängelt: jie würben bielmehr begriffen haben, baß ein wah

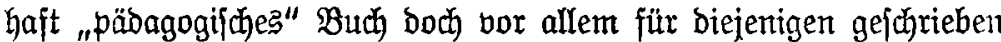

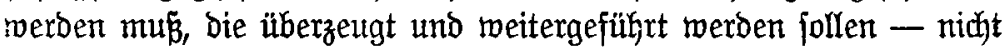
bloß̧ für biejenigen, welche bereits überzeugt fint unt anberwärts genüg ende Belegenheit finden, fith in ihren eigenften Seilig. tïmern zu befeftigen.

Bon freibenferifacer Seite ift lebhaft beflugt worben,

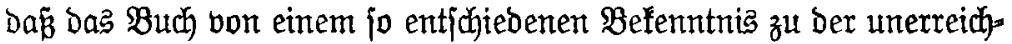
baren päbagogif dhen Araft ber driftlidjen Religion getragen ift. Der Berfaffer betont barum nodhmals ausbrülutich, dá biejes Befenntniz nicht aus einer beliebigen metaphyfifichen Iaune, fonden gerabe aus bem $\mathfrak{R} e r \mathfrak{n}$ feiner moralpäbagogifden Stubien

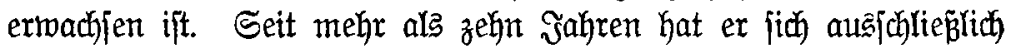

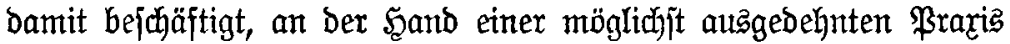
Der etfifichen Jugentounterweifung bas \$robfem ber Sharnfterbildung

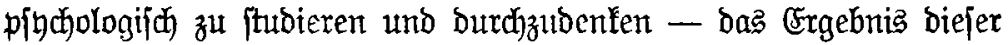
Stubien ift bie Einficht in bie abjolute päbagogif he 11nzulänglichleteit aller religionalojen sugenderziehung *). Und ber Berfafjer ift über=

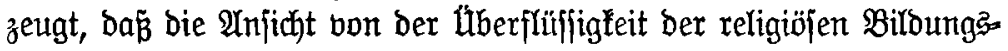
mittel nur beshalb jo meite freife moderner \$äbagogen zu beherrichen vermag, weil biefelben auf bem (s) ebiete ber charafter=

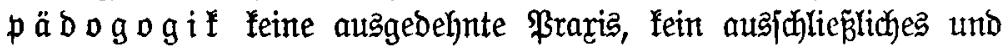
fonzentriertes Studium hinter fich haben. Yuf biejen Umitand mus um ber Sache willen ausbrüfflich hingetwiejen rerben - weil hier bon philopphijden-Sdriftitellem und von blo

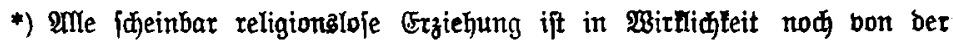

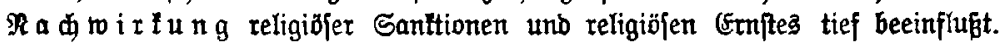
Erft in ber fommenben Generation wiro man beutficher erfahren, was eigentlich religionaloje cratehung bebeutet. 


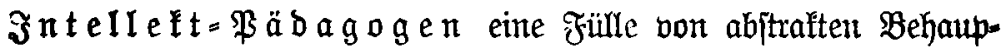
tungen aufgeftellt worben find, bie mit ben wirflichen Tatfachen uno

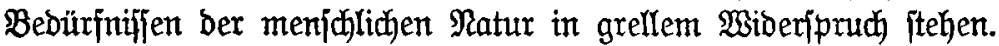
Sein Moralgebot bermag bie Seele bes Menfdien fo in ihrer eigenften Sprache anzureben mie bie driftliche Religion, feines fo ben Sehorjam mit ber Befreiumg, Dag "Stirb" mit Dem "Werbe", bą Dpfer mit ber 2ruferitehung zu vermählen. Wirb bies erit wieber erfannt merben, fo wirb man einjehen, dap bie religiöje Begrünoung Der (Ethif nidyt

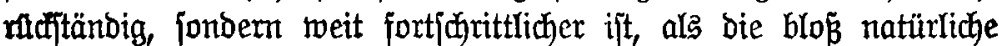
Sittenlehre - eben weil jene bas äupere Bebot in bas per[önlidujte Leben zu überfeben weif und Darum bas übermindet, was ßauluz bie "Inedhtichaft des (sefeses" nennt und wa弓 ber Moral gerabe bei itarf perjönlich beranlagten Menjahen oft jebe Mirffamleit nimmt.

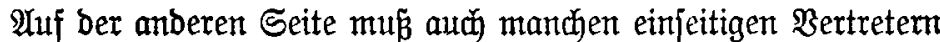
ber firdhliden \$äbagogif gejagt werben, Dá bie majeftätifdye (se= bärbe, mit ber fie bie etbif den Beftrebungen freigejimter freife ableknen, nidjt ber unbejtreitbaren Bebeutung geredit wirb, weldhe diefe Beitrebungen in Der gerwaltigen Aulturfrife ber Begenmant haben. (F⿱

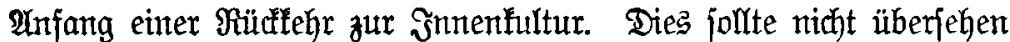

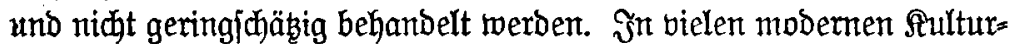
zentren wadjen boch bie von Der Mirche abgefallenen Bolfzitreife

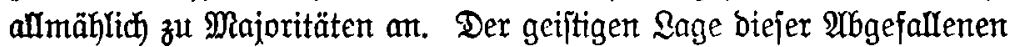
wirb aber weber burd einen ergatwgenen Religionsunterricht, noch

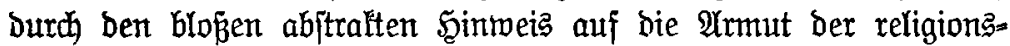
lofen Moral und auf bie überlegene Rebensfülfe ber wrifllichen Religion ridtig geholfen. Denn wenn nicht ftatt biejer হebensfülle fo erichrectend

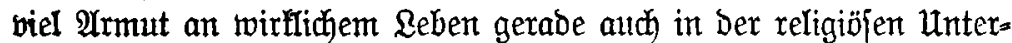
roeijung wäre, fo hätte man wohl nidht eine jo groß̉e Bahl bon $\mathfrak{Y l b}$, gefallenen zul beflagen. Man rebisiere baher auf religiöfer Seite bor alfem bie eigene Methode, bamit fie wahrhaft Beugnis ablege

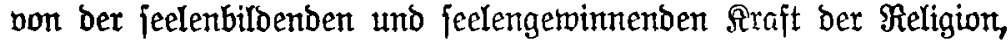
und man ahte im abbrigen alle jene ethifhen Bejtrebungen zunähji als erfte Schritte ber Umfehr bon aufen nad innen; man betrachte fie femer aud als unentbehrliche neut $x$ a le Methoden inmitten foldher Anjtalten und Bereinigungen, Die inrem $\mathfrak{W e j e n ~ n a d y ~ i n ~ b e r ~}$ Bintrbensfrage nidt ßartei nehmen sürfen. Bu befämpfen braudt 
man fie nux bort, wo fie aus ifrer prat auf rein ethijhe 2 Intregungen ein Dogma von ber (Entbehrlidfeit ber

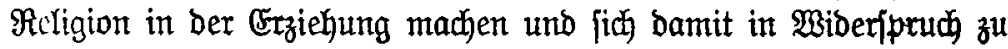
ber Erfahrung alfer sahthunderte fekęr.

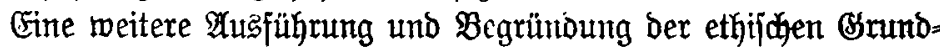
gebanfen bes borliegenden Budjes foll in einem weiteren Bude gegeben werben, Das unter Dem Iitel "Rebensführumg" im Saufe

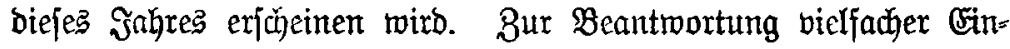
wänbe gegen ben religiöjen Stambpunlt bes Berjaffers wirb - eben=

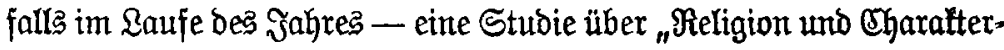
billoung" exicheinent).

Büriđđ), ìn März 1907.

ริr. $\mathfrak{x}$. Foexfter.

\section{Drittes Bormort.}

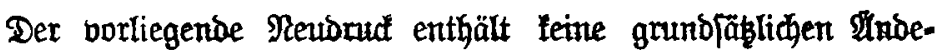
nungen. Start umgearbeitet und ermeitert wurben nur bie $\mathfrak{A} u z$ a fülynungen über bie päbagogijohe Behandlung ber \&äge (S. $316 \mathrm{ff}$.). Der Beridyt liber bie Lage des ethifben untertichts in England wurbe Durch Mitteilungen über midgtige neutere Entwictlungen ergãnżt (ङ. 190). Enolich wurbent in bas Rapitel ûber bie $\mathfrak{B e}=$

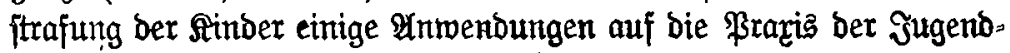
gerichte eingefingt (ङ. $700 \mathrm{ff}$. ).

Bürid, im $\mathfrak{M} \mathfrak{R} 1909$.

ช̛r. 23. Foeriter.

1) Die Pubfifation biefer Studie ift noch verfioben worben, ba ber Berfaîjer biejelbe zu einer primgiellen unterfuchung exweitern wir. 